\title{
Early Health Related Behaviours and their Impact on Later Life Chances: Evidence from the US
}

\author{
Simon M Burgess \\ and \\ Carol Propper
}

\section{Contents}

I. Introduction

II. Literature

III. Data

IV. Estimation Strategy

V. Results

VI. Conclusions

References

Tables and Figures

CASEpaper

CASE/ 6

February 1998
Centre for Analysis of Social Exclusion

London School of Economics

Houghton Street

London WC2A 2AE

CASE enquiries: tel: 01719556679 


\section{Centre for Analysis of Social Exclusion}

The ESRC Research Centre for Analysis of Social Exclusion (CASE) was established in October 1997 with funding from the Economic and Social Research Council. It is located within the Suntory and Toyota International Centres for Economics and Related Disciplines (STICERD) at the London School of Economics and Political Science, and benefits from support from STICERD. It is directed by Howard Glennerster, John Hills, Kathleen Kiernan, Julian Le Grand and Anne Power.

Our Discussion Papers series is available free of charge. We also produces summaries of our research in CA SEbriefs. To subscribe to the series, or for further information on the work of the Centre and our seminar series, please contact the Centre Administrator, Jane Dickson, on:

Telephone:

Fax:

Email:

Web site:
UK+171955 6679

UK +171 2422357

j.dickson@se.ac.uk

http:/ / sticerd.Ise.ac.uk/ case.htm 


\section{Editorial Note}

Simon Burgess is a Reader and Carol Propper is a Professor in the Department of Economics, University of Bristol, and both are associates of CASE.

\section{A bstract}

This paper uses evidence from the US to examine the impact of adolescent illegal consumption and violent behaviour on later life chances. Specifically, we look at the effect of such behaviour by young men in late adolescence on productivity and household formation ten years on. We find that alcohol and soft drug consumption have no harmful effects on economic prospects in later life. In contrast, hard drug consumption and violent behaviour in adolescence are both associated with lower productivity even by the time the individuals are in their late twenties. These effects are substantial and affect earnings levels and earnings growth. These results are robust to the inclusion of a rich set of additional controls measuring aspects of the individuals' backgrounds. However, we find no evidence of any of these behaviours significantly affecting household formation. 


\section{Introduction}

The availability of panel data of long length makes it possible to study the impact of events which occur early in an individual's life on its later course, and so to test the assumptions that may be made in public debate about the effect of early behaviours on later life outcomes. The focus of the present paper is on the impact upon later life of behaviours and events which are sometimes portrayed as anti-social or deviant, or which affect individual's early physical or mental health. The early behaviour we examine includes the consumption of alcohol and illegal drugs, aggressive physical behaviour, evidence of family stress and poor health which limits employment. The paper examines the impact these behaviours have upon subsequent productivity and household formation.

The approach taken in this paper is to use a human capital framework and to treat these events as damaging to early health, and to examine their impact on later productivity and household formation. Our approach differs from some of the recent papers we discuss below, which tend to examine contemporaneous consumption and productivity: we examine the impact of early health damaging behaviours on later outcomes.

The damaging early events may take the form either of a negative shock to health capital (in this category we examine an early health event that limits an individual's ability to work and the event of running away from home), or consumption or other behaviour that may damage health (in this category we examine alcohol and drug consumption and violent behaviour). The aspects of later productivity that we examine are earnings, employment status and earnings growth. The measure of household formation is time to marriage. Finally we examine the impact of early events on poverty status. As being poor is typically the outcome of both labour market and household decisions (Burgess and Propper 1996), poverty status can be viewed as a summary reduced form measure of the impact of early events on both labour market productivity and household formation.

The approach of our work is most similar to the US studies of early health events on later earnings and wages, most commonly analysed using older workers (e.g. Chirikos and Nestel 1985). There are some studies of younger workers and alcohol consumption, but the time period used between consumption and the later events is considerably 
shorter than in the present study (Bryant et al 1993). For example, using the same data set as we use here, Byrant et al (1993) examine the impact of drinking patterns between 1982 and 1984 on the wage change for the period 1982 to 1985 . They found higher drinking levels were correlated with higher wages and hours of work. Over time however, increased drinking was associated with lower wages.

We find that for men a number of adolescent behaviours are associated with worse labour market outcomes a decade later. Specifically, we find that earnings and labour market participation for men in their late twenties are negatively affected by the following behaviours in their adolescence:

- $\quad$ heavy substance use (abuse)

- violent behaviour

- $\quad$ extreme violence

- $\quad$ running away from home, and

- $\quad$ being restricted in work for health reasons.

On the other hand, later earnings appear not to be affected by adolescent indulgence in:

- light substance use

- under-age alcohol consumption

While the impact on labour market behaviour is clear, there is less impact on household formation. However, as early marriages are more likely to end in divorce, there may be an impact on household dissolution.

The remainder of the paper is organised as follows. Section II provides a survey of previous related literature. Section III discusses the data set and our sample, focusing particularly on the measures of health shocks that we will examine. Section IV outlines our econometric approach. Section $V$ gives our results. Section VI concludes.

\section{Literature}

The impact of some of these behaviours has received increasing interest from economists in recent years ${ }^{1}$. Recently in the US a number of papers

1 Economists are relative latecomers to this field, and have typically focused on economic outcomes related to productivity (earnings, employment status, poverty). Sociologists, typically also relying on large scale data sets, have been more directed towards the effects of early deviant or antisocial behaviours on status, be it either 
using economic approaches have examined both current and early consumption of alcohol on human capital acquisition and productivity (e.g. Cook and Moore 1993; Mullahy and Sindelar 1993, 1995; Kenkel and Ribar 1994; Yamada et al 1996). Recent work has paid particular attention to the issues of econometric modelling and causality. The research findings are quite mixed, but most of the current empirical literature has substantiated the commonly held view that 'problem drinking' is associated with lower earnings, lower employment rate and greater unemployment. Properly allowing for simultaneity appears to strengthen these results (e.g. Mullahy and Sindelar 1995). There has also been interest in the impact of early alcohol consumption on family dissolution (Mullahy and Sindelar 1994) which suggests that early problem drinking is associated with greater propensity to divorce.

There are some studies of alcohol consumption on the later earnings of young workers, but the time period used between consumption and the later events is considerably shorter than in the present study (Bryant et al 1993). For example, using the same data set as we use here, Byrant et al (1993) examine the impact of drinking patterns between 1982 and 1984 on the wage change for the period 1982 to 1985. They found higher drinking levels were correlated with higher wages and hours of work. Over time however, increased drinking was associated with lower wages.

The commonly accepted notion is that illegal drug use is negatively associated with earnings, validating the increase in employment related drug testing in the US. However, two recent studies, both using 1984 data from the NLSY, and allowing for simultaneity in drug use and wages, challenge this view. Gill and Michaels (1992) find that once allowance is made for self-selection effects, drug users actually received higher (current) wages than non drug users. The same authors' analysis of employment effects found that all (soft and hard together) drug users had lower levels of employment, but that hard drug users did not. Register and Williams (1992) estimated standard log wage equations, controlling for the probability of employment and allowing marijuana and cocaine use to be endogenous. They found that while long term and on-the-job use of marijuana are negatively related to wages, general marijuana use has a positive effect. No significant effects for cocaine use were found.

occupational and economic status, or social status (or the lack of such status). Increasingly these approaches converge. 
There are clear patterns of association between drug consumption and education (drugs causing individuals to drop out of school earlier e.g. Mensch and Kandel 1988) and drug consumption and adolescent household formation. Drug use has been shown to be associated with teen pregnancy (e.g. Mensch and Kandel 1992) and fatherhood (Elster et al 1987).

To our knowledge fewer economists have examined the effect of early 'anti-social' behaviour on attainment, though deviant behaviour, including violence, has long been of interest to sociologists and psychologists. For example, research using the NLSY shows that there is a relationship between behavioural and school problems and adolescent fatherhood. Academic, drug consumption and conduct problems were significantly more common amongst adolescent fathers than non-fathers (Elster et al 1987). Windle (1994) found runaway (from home) status in early adolescence (14-15) to be significantly associated with subsequent (four years later) substance abuse, alcohol problems and school drop-out status.

Of late, economists have been turning their attention to the links between delinquent behaviour and marriage (e.g. Akerlof 1997). If a tendency to violence is treated as a indicator of mental instability or ill health i.e. as a component of health capital defined to include both mental and physical capital, then these behaviours can be viewed as part of the impact of early health capital accumulation upon later productivity or demographic events. Support for such an approach is given by the fact the high correlations between behaviours such a problem drinking, violence, and poor physical health (National Commission on Children 1991).

It is well established that there is a correlation between poor health and employment. Few studies have examined the limited health status data in the NLSY for young adults. However, there is considerable evidence from older workers that health problems in the past adversely effect current earnings (e.g. Chirikos and Nestel 1985), wages and hours (Chirikos and Nestel 1982), though the legacy of ill health differs substantially by race and genders, blacks being less able to sustain labour market activity and earnings when faced with a health problem.

\section{Data}


The data we use in this paper are taken from the $\mathrm{N}$ ational Longitudinal Survey of Youth (NLSY). This is a US panel dataset running from 19792, containing data on 12686 people aged 14 - 22 in 1979. One significant feature of the data is the effort put into tracking respondents, and consequently attrition from the sample is minimal: in 1990, 90\% were still interviewed. The NLSY consists of three samples: a representative sample of youth (6111 people), a supplemental sample of young hispanics, blacks and disadvantaged non-hispanic/ non-black (5295), and a military sample representing youth serving in the armed forces in $1978^{3}$ (1280). The NLSY supplies weights to account for the oversampling of some groups, and to produce representative group population estimates in tabulations ${ }^{4}$. It provides a great deal of data on family background and the early experiences of respondents, as well as subsequent labour market outcomes and household structure. In this analysis, we use only civilian respondents.

The key variables that we focus on arise from questions asked in 1980. These therefore relate to the choices and experiences of the respondents as adolescents ( $90 \%$ are between the ages of 16 and 22 ). The questions were preceded by the following preamble:

On this form are descriptions of types of activities that some young people can get into trouble for. I want you to read each item, and put a check mark after the category which best describes the number of times in the last year you have done the activities described.

The answers were coded in seven bands (see table 1). The questions are:

(1) Times run away from home in past year

(2) Times drank alcoholic beverages past year (drank beer, wine, or liquor without your parents' permission)

Both these questions were only asked of those aged 17 or under.

(3) Times seriously threatened to hit, or actually hit someone in past year

(4) Times attacked with intent to injure or kill in past year (attacked someone with the idea of seriously hurting or killing them)

2 The survey is on-going; we use data through 1992.

3 This last sample was dropped in 1985 and the economically dis-advantaged whites were dropped after 1990.

4 The analysis below reports weighted distributions (Table 1), but unweighted regressions. 
(5) Times smoked marijuana/ hashish in past year

(6) Times used other drugs/ chemicals to get high in past year (used any drugs or chemicals to get high or for kicks, except marijuana)

To this set we added a further variable recording the existence of a work-related illness in the respondent's early labour market career: namely, whether the respondent was restricted for health reasons in the amount or type of work they could do (before the age of $\mathbf{2 0}$ for high school graduates or 23 for men with some college education).

We chose to focus our analysis on male respondents only. This was because we wanted to treat these seven behaviours or events symmetrically and few women reported violent behaviour: for example, $94 \%$ of women claimed never to have seriously attacked anyone, and $73 \%$ claimed never to have hit anyone. The gender differences in the distributions of answers on illegal consumption are much less marked, but given our desire for a consistent treatment, we restricted our sample to men 5 .

The distributions of these variables is shown in Table 1. A number of points stand out. First, as might be expected, violent behaviour is relatively rare. While around half of the men said that they had hit or threatened to hit someone at least once during the year, extreme violence (defined as in question (4) above) is restricted to a small minority. There is no evidence for any differences between black and white men in terms of the distribution of the use of violence.

The data show that running away from home is a very rare experience for this sample, with only $9 \%$ reporting this. $N$ ote that this is only asked of respondents under the age of 18 , resulting in a reduced sample size.

The illegal consumption of alcohol (i.e. among under-18 year olds), soft and hard drugs is rather more common. A bout half of respondents reported use of marijuana, and half (blacks) or three quarters (whites) reported under-age drinking. For both of these activities, among those admitting any consumption, frequent use is as likely as occasional use. Use of hard drugs is less common, about $25 \%$ and $20 \%$ of whites and blacks admitting to this. It is interesting to note, that while the distributions for behavioural variables such as violence and running away from home, are very similar between the two races, illegal consumption is more common among whites.

5 We also eliminated hispanic men as the sample sizes were insufficient. 
Episodes of ill-health that restrict the individual's work options are also rare. The proportion who are restricted are similar for blacks and whites.

It is also useful to explore the correlation between these variables, and these are reported in Table 2. The most striking fact is that all bar two numbers in the table are positive: most of these behaviours tend to occur together. Similar activities tend to be correlated: for example, violent behaviour (hitting, question(3)) is correlated with extreme violence (question (4)), and consumption of hash is correlated with under-age drinking and the use of hard drugs. Neither the act of running away from home, nor the occurrence of work-restricting illhealth are highly correlated with the variables, apart from a correlation of 0.34 between extreme violence and running away among black men.

The likelihood of measurement error seems higher than usual in questions of this sort. This may take two specific forms. First, some respondents may under-report illegal activity in case this is passed on to the authorities. If this is a substantial problem, then we would expect to see a smaller difference in outcomes between those reporting the activity and those not: our estimates will be an underestimate of the truth. Second, some respondents may over-state their involvement in these behaviours as part of adolescent male braggadocio. The interpretation of our results would then depend on the correlation of such mis-reporting with other underlying characteristics: if it were purely random, then we would again expect to find nothing. Otherwise, the results will still tell a story: lying that one attacks people with intent to seriously injure them on a monthly basis may not be indicative of a sound underlying mental state.

\section{Estimation Strategy}

\section{Conceptual Framew ork}

We use the same conceptual framework to examine the impact of each of these early health related behaviours upon later life. We assume that there is some causal relationship running from the early behaviour or event (D) to later labour market and household behaviour (E). E is a choice variable that will depend upon current observable exogenous variables (X), the past behaviour or event (D) and unobservable (to the researcher) individual characteristics or shocks (u), i.e. 


$$
E=E(X, D, u)
$$

$D$ itself is also a choice variable and so will be a function of other exogenous variables $(Z)$ (which may include, amongst other things, prices and contain some of the same variables as in $\mathrm{X}$ ), the background variables (W) and some other unobservable individual characteristics (e) i.e.

$$
\mathrm{D}=\mathrm{D}(\mathrm{Z}, \mathrm{W}, \mathrm{e})
$$

Our focus is on the estimation of (1) for a number of events in the set $E$ (labour supply, earnings, marriage, poverty). If the dependent variable is (a measure of) labour supply then we can interpret estimation of (1) as estimation of a conventional labour supply function conditional on the behaviour event $D$ i.e. in the class of models which have examined productivity. If the negative event is interpreted as a health shock or a reduction in health as we do here, then estimation of (1) is in the class of models which have examined the impact of health on labour supply. If the dependent variable is time to marriage then the focus is on demographic effects of early health shocks or events on marriage. Poverty is a summary reduced form measure of both labour supply and demographic events, so estimation of (1) with poverty status at an age as the dependent variable is estimation of both the indirect and direct effects of early health related events on later life.

Estimation of (1) raises at least two econometric issues. The first is simultaneity, the second unobserved heterogeneity which leads to correlation between e and $u$. If $D$ and $E$ were choices made at the same time then estimation of (1) would beg questions of causality. For example, does alcohol consumption lead to poor labour market performance, or does poor labour market performance (for example being made unemployed) lead to problem drinking? Or, as consumption of drugs and alcohol are normal goods, an increase in earnings will lead to an increase in consumption of drugs and alcohol. The valid econometric approach would be to instrument D (for example, Mullahy and Sindelar 1994, Kenkel and Ribar 1994).

In our case, we do not have a problem of simultaneity, as D is an event which has happened in the past. However, we are still left with the problem that both $D$ and $E$ may be caused by the same factors (for example, family background, a taste for leisure). If this is the case, with $W$ omitted from (1) the coefficient on $D$ will be a combination of the direct effect of $D$ on $E$ (the causal relationship we seek to investigate) 
and the indirect of the background variables on $\mathrm{D}$ and so on $\mathrm{E}$. One solution would again be to instrument $D$, but a problem with this approach is the paucity of valid instruments. Apart from prices or laws which restrict availability (which are applicable for the consumption events only) it is difficult to think of background variables that should be in (2) but excluded from (1).

To deal with this problem, we include in equation (1) all observable factors which we think may determine both $D$ and $E$ i.e. those measures in $\mathrm{W}$. So we estimate

$$
E=E(X, D, W, u)
$$

In other words, we condition on those factors which we think may affect $D$, and then examine the net effect of $D$ on $E$. For this to be a valid procedure we must assume that we have measures of all those variables which affect both $D$ and $E$, in other words there are no variables in $u$ and e that are correlated. So we impose the assumption of no correlation between $u$ and e, conditional on inclusion of $\mathrm{W}$ in (1).

Comparison of the result of estimation of (1) and (1') provides evidence of whether $D$ exerts a impact on $E$ that is direct. If the estimates do not change then we can infer that the partial effect of $D$ is not due to the conditioning variables for which we have measures. As theory often does not provide very good guide as to what should be included and what excluded from equations such as (1) and (2), presentation of estimates for (1) with and without W provides a test of what would be good instruments for $D$. If the estimates do not change it suggests that the variables we select to be in W (discussed below) would not be good instruments.

As our data does not distinguish between individuals who engaged in early events detrimental to health and who subsequently stopped and those who continue to consume, estimation of ( $\left.1^{\prime}\right)$ is essentially estimation of a reduced form equation. That is we cannot separately identify the impact of continued consumption from the persistent effects of early consumption. However, the question of whether early consumption or anti-social behaviour is bad for later life still remains a valid issue to address.

\section{$2 \quad$ Measures of $E$ and estimation strategy}

We examine a number of measures of later productivity: earnings on average ten years on (at age 28), earnings growth, mean earnings over 
the period 1981-92, and whether the individual is poor at 28. Estimation of (1) is by OLS for the continuous variables and logit analysis for the binary variable. Estimates are given with and without the background variables W.

The measure of household formation is time to first marriage or cohabitation (i.e. formation of a stable partnership). We specify the hazard as logistic with a piecewise constant baseline

$$
h(t)=1 /\left(1+\exp \left(-\gamma(t)-\beta^{\prime} x_{t}\right)\right.
$$

(3) allows the baseline hazard to vary over time. Estimation of (3) in discrete time is equivalent to estimation of a logit model where the dependent variable has value 1 in the year in which marriage/ cohabitation took place and is 0 otherwise and is commonly used in duration modelling (Jenkins 1991). We do not estimate unobserved heterogeneity on the grounds that we undertake all estimates separately by race and include a full set of $W$ variables.

Because the events in D are quite highly correlated we wish to test whether significant effects remain once the joint impact of these events is analysed. Therefore after estimation of (1) using each measure in D, we reestimate (1) using 5 of the 7 measures of the set $D$ together as regressors (plus the $X$ and $W$ vector where appropriate). We use only 5 because alcohol consumption and running away from home are asked only of those under 18, so inclusion of these variables considerably reduces the sample size.

\section{Specification of Covariates ( $X$ and $W$ )}

The specification of the $X$ vector of structural covariates and the $W$ vector of background variables is slightly different in the equations measuring productivity from that estimating time to marriage, since the two are rather different decisions and may be expected to depend on different factors. For earnings at age 28 , earnings growth, mean earnings over the period 81-92, and poverty status, the $X$ vector contains years of education, the local unemployment rate, year dummies, marital status, lagged to reduce problems of simultaneity, whether the individual had children, lagged to reduce problems of simultaneity. The $\mathrm{W}$ vector of background variables contains measures of parental attainment and work status (mother did not complete high school, father did not complete high school, mother worked when respondent was 14, father worked when respondent was 14), whether living with both parents at 
age 14, whether the individual had religious upbringing, whether lived in the South at 14, number of siblings whether lived in an urban area in 1980. All these variables have been argued to affect al cohol consumption and other early behaviour.

For the time to marriage equations we do not specify separate $X$ and $W$ vectors, as many of these variables which are hypothesised to determine time to marriage are the same as the background variables used in the productivity equations. The variables in the time to marriage equation were intended to capture both attitudes to marriage and a set of income related variables measuring the relative financial gain from marriage, plus age and education. The choice of these variables was based on previous work by ourselves and others analysing the determinants of household formation and dissolution within young American adults (Burgess et al 1997). The variables were age, age squared, highest level of education, whether living with both parents at age 14, whether the individual had a religious upbringing, the parental education and work status variables, the extent to which the respondent help traditional attitudes to the family and women's labour force participation, respondent's own earnings, lagged to avoid simultaneity, the income of the household lived in prior to marriage (lagged), and the wage rate of potential partners. This last variable is a measure of mean earnings of potential marriage partners for the respondents and is constructed using information on the respondents age, educational status, state of residence and the earnings distribution of member of the opposite gender conditional on these variables. Further details are provided in Burgess et al (1996).

As noted above all estimates are made separately for blacks and whites. Previous research has found systematically differences in the relationship between alcohol consumption and gender and age (e.g. Mullahy and Sindelar), and alcohol consumption and race (e.g. Yamada et al). Much labour market research indicates significant differences between races. We therefore wished to allow for systematic differences across races in the relationship between negative health events and shocks and labour market and marriage outcomes.

\section{Results}

We first present pictures of the one way associations between the productivity measures and the measures of early health shocks. This 
both establishes that there are issues to be addressed and gives baseline relationships with which our econometric results can be compared.

Figure 1 shows mean log earnings by age and the frequency of the event. Panel 1 shows a clear negative association between earnings and extreme violent behaviour, though the small number of observations in the frequent category means the series are rather noisy. Frequent hard drug use shows a small but consistent (over time) negative effect, whereas marijuana use shows no effect. Similarly Panel 4 shows that under age drinking has no persistent negative effect: indeed a small positive effect if anything. Panel 5 indicates that whites who hit others frequently have consistently lower earnings; the picture for blacks is less clear. Panel 6 is rather noisy but indicates that blacks those who run away from home have lower earnings while there is no clear pattern for whites. Finally, early work related health shocks have persistent effects on earnings for whites, while for blacks the early negative effect has disappeared by the late 20 s.

The estimates of equations (1) and (1') are given in Table 3: for white men in Table $3 a$ and those for black men in Table 3b. Before analysing the results in detail we highlight the main results. First, the results change little when we condition on background variables, as well as the $X$ vectors. In other words, the estimates of the impact of early health related shocks is unaffected by the addition of variables which may themselves affect the level of health related shocks. This suggest that the behavioural variables are not simply picking up the lingering effects of particular backgrounds. In other words, the assumption of exogeneity of these shocks to the later events under examination (conditional on the set of variable we assume determine the shocks) may not be invalid for this age and gender group.

Second, several of the estimates of the impact of early events are well defined and of consistent sign across the two races. They indicate that there is a negative relationship between several of the early negative health related events or behaviours on productivity, but that these events appear to have little effect on the propensity to form households. The impact on poverty is less than for earnings but greater than for marriage, which fits with the fact that poverty is a reduced form measure that incorporates both labour market and household behaviour.

We report first the findings for the effect of early health related behaviour on productivity i.e. earnings at 28 , mean log earnings growth 
and mean labour supply. We examine first white men and then report similarities and differences with the results for black men.

\section{Illegal consumption behaviour and productivity}

Looking first at under-age alcohol consumption, it is clear that consumption per se has no negative impact on productivity up to 10 years later. In fact, the only significant relationships are positive ones: under-age consumption appears to increase log earnings 10 years on and to increase mean earnings over the subsequent 10 year period. Thus the direct effect of alcohol consumption is, if anything, to raise earnings. This result does not measure the indirect affect such consumption may have on educational attainment, which is of course a significant determinant of earnings. Early alcohol consumption may have a negative effect on educational attainment and our results do not examine this indirect - and more short term - effect ${ }^{6}$.

Our findings that alcohol consumption per se is not economically harmful is supported by considerable other research which suggests that it is excessive alcohol consumption which is damaging, not moderate drinking per se (e.g. Mullahy and Sindelar 1995). To examine this using the NLSY data we reestimated all the equations replacing the continuous measure of alcohol consumption with a dummy variable indicating whether the individual was a frequent drinker (drank at least once a week). However, the results indicated no negative effect, but the coefficients were 0 rather than positive as in Table 3. It appears that for males under the age of 30 under-age alcohol consumption does not appear to lower productivity during the following 10 years after the event.

For all measures of earnings (earnings at 28, mean earnings, earnings growth) the picture is similar for marijuana use. None of the coefficients on marijuana use are large; none is significant at the 5\% level. These results confirm the simple associations in figure 1 . However, the relationships between use and mean labour supply is different: marijuana use is significantly associated with a lower participation rate.

When we examine heavy drug use (consumption more than 50 times per year in the year in which the question was asked) a different picture emerges. Heavy use prior to age 18 is associated with lower

6 Yamada et al (1996) find a small and nearly significant negative effect of under age alcohol consumption upon the probability of high school graduation. 
earnings, both 10 years on and across the whole 10 years between 18 and 28. While the association between use prior to age 18 and earnings growth is positive, perhaps indicating some catch-up after the lower initial earnings by those with heavy consumption, the small size of the positive coefficient bears out the fact that levels remain below those of non-heavy users. The impact on participation rates is negative and large, with and without background controls. Clearly heavy drug use has a much more negative effect on productivity than any drug use.

The picture for the effect of these three consumption activities for black men is very similar, though in general the coefficients are less well defined owing to the smaller sample size. Under age drinking and consuming marijuana have no negative impact on earnings, though as for white men, marijuana use does reduce labour supply. On the other hand, early heavy drug use has a large negative impact on both the level of earnings and on labour supply.

As noted above, as we do not know whether individuals continue to consume after under-age consumption, we cannot separate out the effect of early consumption followed by non-consumption from early consumption followed by continued consumption. What the results show is that early consumption of alcohol and marijuana is not associated with later lower earnings, but early consumption of heavy drugs is. There are of course all sorts of possible explanations. It may be that early heavy drug use means addiction, and so subsequent drug use, while light drug use does not. Or it may be that early heavy drug use is associated with other activities which lead to lower earnings (for example activities which increase the chances of being imprisoned) while light drug use carries a lower probability of engaging in such activities.

Table 2 shows relatively high correlation between consumption of alcohol and drugs. It is therefore of interest to see whether the results of Table 3 persist when the joint effect of such consumption are analysed. Table 4 presents the estimates when 5 of the 7 measures of early behaviour are included together as regressors. The results indicate that the negative impact of heavy drug use on both earnings and labour market participation remains, even after conditioning for the other early behaviours. The effect of marijuana use on later earnings is still positive and the effect on participation rates still negative, though these coefficient on mean labour supply for white men is absolutely smaller and less well defined. It appears whether we take a single measure of 
illegal consumption or consider the impact of two such activities together, heavy drug use has harmful effects on both participation and earnings. On the other hand, marijuana use affects participation, but conditional on being employed, does not appear to affect earnings 10 year on.

\section{Violent behaviour and productivity}

Figure 1 indicates violent/ aggressive behaviour is associated with lower earnings for both white and black men. The graphs show this relationship exists if we do not condition on those factors which may affect earnings: the results of Table 3 indicate that conditional on other factors which affect earnings, early violent behaviour whether extreme or not is clearly associated with lower productivity.

\section{Early work-related health shock and productivity}

The results of tables $3 \mathrm{a}$ and $3 \mathrm{~b}$ indicate that an early work related health shock reduces earnings, depresses means earnings and reduces average labour force participation for both races. The similarity of the estimates with and without background variables indicates that if these results are caused by an individual fixed effect, this fixed effect is not measured by the set of commonly used background variables available in this data set.

These results are of interest. First, it is interesting in the context of findings for alcohol which indicate the impact on participation may be more important than the impact on earnings of those in work, that the largest impact is in terms of participation rather than earnings. It is also of interest that the patterns for earnings growth differs from that for the levels. For both races earnings growth is not depressed by the work related health event early in life, and for black men, earnings growth is positively associated with this variable. The effect of the health shock on the levels means that while earnings rise more rapidly they do not do so at a sufficient rate to overcome the depressing effect that having such a condition early in working life has on productivity.

Finally the results for running away from home indicate that this behaviour again affects productivity, particularly for white men and particularly through its effect on subsequent labour supply as distinct from earnings. As for early health shocks, earning growth is actually positively associated with running away from home in early adulthood, 
but this is not surprising given the low level of earnings this group have at age 18 (as is clear from Figure 1).

\section{The impact of early health related events on marriage}

In contrast to the negative effects that these shocks or behaviours have upon productivity, there is little association between these events and household formation for either races. The only variable which is (highly) significant is running away from home and this only for black men. This event is positively associated with marriage, perhaps because some individuals run away from home to form a partnership (note that our marriage variable is defined as marriage or cohabitation in a stable relationship.) Again moderate consumption of illegal drugs and alcohol appear to have no negative effects, but heavy drug use does appear to delay household formation, thought not significantly so. When all shocks are examined together the impact of drug consumption remains.

\section{The impact of early health related events on poverty at age 28}

Our results indicate exactly the same patterns of association between these events and poverty for both black and white men. The estimates are well defined only for whites. Poverty at 28 is positively associated with work related health shocks, heavy drug use, extreme violence, and running away from home at 18 or younger. It is negatively associated with alcohol and marijuana use. Again the patterns of association with moderate consumption (some al cohol use, softer drugs) mirror our other findings: consumption of these substances in adolescence per se does not appear to have a negative impact on later life. The findings that only heavy drug use and extreme violence are associated with being poor again mirror the rest of our findings: this extreme behaviour does have persistent negative effects.

The event with the largest impact on the probability of being poor is having early health shocks that prevent work. While the absolute magnitudes of the coefficients on the various earnings equations for this variable are in the higher range, the coefficients for this variable do not have the highest effect on productivity (for example running away from home has a similar impact on mean labour supply, whilst heavy drug use and violence have a larger (absolute) impact). The very high estimate of the effect of an early health event which limits work for the poverty rate could reflect of the effect of this variable on the variance in earnings. The poverty rate is not only a function of household formation 
and labour market decision, but is a measure of the number of persons in the lower tails of the income distribution. If there are a subset of individual with early work related health shock who continue to get these shocks, then this group is likely both to earn less when in work and to work less. The combination means that they are more likely to be in the lower tail of the income distribution.

The results for poverty remain broadly unchanged when all 5 indicators of early shocks are analysed together, with the exception of the effect of violent behaviour. The effect of this variable on poverty is negative for both groups when all events are examined together, whereas analysed on its own its impact on poverty for white men is weakly positive. Given that we are conditioning in table 4 on extreme violence, and the effect of this event has become slightly stronger for both race groups, the change in the coefficient estimate on lesser forms of violent behaviour is not surprising. The results using all 5 variables tell the same story as the analyses for each factor separately: extreme behaviour and an early health event which limits work depresses life chances.

\section{Conclusions}

The paper has examined a set of behaviours which could damage current or future health on future earnings, labour market participation and marriage. We find clear patterns in the results, often well defined coefficient estimates, and similar estimates for both black and white men. Our results show that there is a negative relationship between several of the early negative health related events or behaviours on productivity, but that these events appear to have little effect on the propensity to form households. The impact on poverty is less than for earnings but greater than for marriage, which fits with the fact that poverty is a reduced form measure that incorporates both labour market and household behaviour.

Specifically, we find that earnings and labour market participation for men in their late twenties are negatively affected by the following behaviours in their adolescence:

- $\quad$ heavy substance use (abuse)

- violent behaviour

- $\quad$ extreme violence

- $\quad$ running away from home, and 
- $\quad$ being restricted in work for health reasons.

On the other hand, later earnings appear not to be affected by adolescent indulgence in:

- $\quad$ light substance use

- under-age alcohol consumption

While the impact labour market behaviour is clear, there is less impact on household formation. However, as early marriages are more likely to end in divorce, there may be an impact on household dissolution.

Our results confirm and extend the patterns found in previous research on alcohol and drug consumption when young. Contemporaneous light alcohol and soft drug use has been shown to have little or no effect on earnings for young men. We show this result extends to earnings and participation 10 years on. We also find, in common with a couple of recent studies, that detrimental effects show up more in labour market participation rates than earnings. 


\section{References}

A kerlof, G (1997), "Men without children”. Paper presented the Royal Economic Society Conference, Stoke, UK, A pril 1997.

Burgess S and Propper, C (1997), "An economic framework for modelling poverty dynamics". Paper presented to the ESRC study group on poverty, LSE, March 1997 (mimeo University of Bristol).

Burgess, S, Propper, C and Aassve, A (1996), "Transitions to independent living, marriage and divorce among Young Americans". Mimeo, University of Bristol.

Burgess, S, Propper, C and Aassve, A (1997), “'I vont to be alone': Transitions to independent living, marriage and divorce among young A mericans". Paper presented at the Royal Economic Society Conference, Stoke, A pril 1997.

Bryant, R, Samaranayake, V and Wilhite A L (1993), "The Influence of Current and Past Alcohol Use on Earnings". Journal of Applied Behavioural Science, 29(1): 9-31.

Chirikos, T N and Nestel, G (1985), "Further Evidence on the Economic Effects of Poor Health". R eview of Economics and Statistics, 67: 61-69.

Chirikos, T N and Nestel, G (1982), "The Economic Consequences of Poor Health, by Race and Sex". Proceedings of the Social Statistics Section, A merican Statistical A ssociation, (1982):473-77.

Cook, P J and Moore, M J (1993), "Drinking and Schooling". Journal of $H$ ealth Economics, 12: 411-429.

Elster, A B, Lamb, M E and Tavare, J (1987), “Associations between behavioural and School Problems and Fatherhood in a National Sample of Adolescent Youths". Journal of Paediatrics, 111, 6(1): 932936.

Gill, A M and Michaels, R (1992), "Does Drug Use Lower Wages?" Industrial and Labor Relations Review, 45, 3: 419-434.

Jenkins, S (1995), "Easy estimation methods for discrete time duration models". Oxford Bulletin of Economics and Statistics, 57: 129-138.

Kenkel, D S and Ribar, D C (1994), "Alcohol Consumption and Young Adults Socioeconomic Status". Brookings Papers on Economic A ctivity: M icroeconomics: 119-161.

Mensch, B and Kandel, D (1992), “Drug Use as a Risk Factor for Premarital Teen Pregnancy and Abortion in a National Sample of Young White Women". D emography, 29(3): 409-429.

Mullahy, J and Sindelar, J (1994), "Alcoholism and income: the role of indirect effects". M ilbank Q uarterly, 72: 359-375. 
Mullahy, J and Sindelar, J (1995), “Employment, unemployment and problem drinking". NBER Working Paper 5123.

National Commission on Children (1991), Beyond Rhetoric: A New A merican A genda for Children and their Families. Washington DC: US Government Printing Office.

Register, C A and Williams, D R (1992), "Labor Market Effects of Marijuana and Cocaine Use Amongst Young Men". Industrial and Labor Relations Review , 45(3): 435-451.

Windle, M (1994), "Substance Use and Abuse amongst Adolescent Runaways: A Four Year Follow-Up". Journal of Youth and A dol escence 1993.

Yamada, T, Kendix, M and Yamada, T (1996), "The Impact of Alcohol Consumption on Marijuana Use on High School Graduation". $H$ ealth Economics, 5(1): 77-92. 
Table 1: Frequency Distribution of Behavioural and Consump

\begin{tabular}{lccccc}
\hline H ow many times in the & & \multicolumn{4}{c}{ \% Distribution } \\
\cline { 2 - 6 } past year? & Violence & $\begin{array}{c}\text { Extreme } \\
\text { Violence }\end{array}$ & $\begin{array}{c}\text { Marijuana } \\
\text { Use }\end{array}$ & D rugs Use & $\begin{array}{c}\text { Under-age } \\
\text { alcohol } \\
\text { use }\end{array}$ \\
\hline White Men & 51.9 & 87.3 & 46.8 & 74.9 & 26.8 \\
Never & 16.5 & 6.5 & 7.0 & 5.3 & 8.5 \\
Once & 10.8 & 2.3 & 4.1 & 4.0 & 5.3 \\
Twice & 12.4 & 1.9 & 7.4 & 5.4 & 14.6 \\
3-5 times & 5.0 & 0.7 & 5.1 & 3.4 & 14.9 \\
6- 10 times & 2.2 & 0.5 & 7.7 & 4.3 & 16.4 \\
11- 50 times & 1.3 & 0.7 & 22.0 & 2.7 & 13.5 \\
More than 50 times & 2709 & 2709 & 2687 & 2688 & 981 \\
Observations & & & & & \\
& & & & & \\
Black Men & 54.7 & 82.6 & 55.6 & 88.4 & 51.9 \\
Never & 22.1 & 9.0 & 12.8 & 4.9 & 13.8 \\
Once & 8.0 & 3.7 & 4.6 & 2.0 & 6.9 \\
Twice & 8.1 & 2.3 & 5.3 & 2.0 & 10.7 \\
3- 5 times & 4.3 & 1.3 & 3.1 & 0.6 & 6.6 \\
6- 10 times & 1.6 & 0.8 & 4.4 & 1.3 & 4.7 \\
11- 50 times & 1.3 & 0.3 & 14.4 & 0.9 & 5.3 \\
More than 50 times & 1128 & 1131 & 1124 & 1111 & 418 \\
O bservations & & & & & \\
\hline
\end{tabular}

Notes:

Weighted using sample weights.

See text for exact questions. These questions were asked in 1980 when respondents were aged $k$ under-age alcohol use and running away from home were only asked of respondents under the 
Table 2: Correlations

\begin{tabular}{lccccc}
\hline \hline & Violence & $\begin{array}{c}\text { Extreme } \\
\text { Violence }\end{array}$ & $\begin{array}{c}\text { M arijuana } \\
\text { Use }\end{array}$ & Drugs Use & $\begin{array}{c}\text { Under-age } \\
\text { alcohol } \\
\text { use }\end{array}$ \\
\hline White Men & 1.000 & & & & \\
Violence & 0.437 & 1.000 & & & \\
$\begin{array}{l}\text { Extreme Violence } \\
\text { Marijuana Use }\end{array}$ & 0.230 & 0.193 & 1.000 & & \\
$\begin{array}{l}\text { Drugs Use } \\
\text { Under-age Alcohol use }\end{array}$ & 0.204 & 0.189 & 0.599 & 1.000 & \\
Run away from home & 0.343 & 0.246 & 0.574 & 0.419 & 1.000 \\
Work-related ill health & 0.178 & 0.233 & 0.293 & 0.284 & 0.203 \\
& & 0.045 & 0.034 & 0.029 & -0.005 \\
Black M en & 1.000 & & & & \\
Violence & 0.452 & 1.000 & & & \\
Extreme Violence & 0.270 & 0.211 & 1.000 & & \\
Marijuana Use & 0.250 & 0.353 & 0.403 & 1.000 & \\
Drugs Use & 0.331 & 0.273 & 0.622 & 0.241 & 1.000 \\
Under-age Alcohol use & 0.125 & 0.343 & 0.194 & 0.287 & 0.052 \\
Run away from home & 0.011 & 0.007 & 0.015 & 0.024 & -0.044 \\
Work-related ill health & 0 & & & & \\
\hline \hline
\end{tabular}


Table 3a: Regression Results: White Men

\begin{tabular}{|c|c|c|c|c|c|}
\hline Dependent Variable: & $\begin{array}{c}\text { Under } 18 \\
\text { alcohol use }\end{array}$ & $\begin{array}{c}\begin{array}{c}\text { Marijuana } \\
\text { Use }\end{array} \\
\end{array}$ & $\begin{array}{c}\text { Heavy } \\
\text { Drugs Use }\end{array}$ & Violence & $\begin{array}{l}\text { Extreme } \\
\text { Violence }\end{array}$ \\
\hline \multicolumn{6}{|l|}{ Log earnings at age 28} \\
\hline (1) Standard Controls(1) & $0.023^{*}$ & 0.002 & $-0.251^{* *}$ & $-0.751^{* * *}$ & $-0.064^{* * *}$ \\
\hline (2) + background controls(2) & 0.019 & -0.002 & $-0.245^{* *}$ & $-0.753^{\text {*a* }}$ & $-0.062^{*+*}$ \\
\hline O bservations & 423 & 1559 & 1560 & 1575 & 1575 \\
\hline \multicolumn{6}{|l|}{ M ean log earnings(3) } \\
\hline (1) Standard Controls & $0.029^{* *}$ & 0.005 & $-0.391^{* * *}$ & $-0.443^{3 * *}$ & $-0.077^{\text {wat }}$ \\
\hline (2) + background controls & $0.035^{* *}$ & 0.003 & $-0.360^{\text {ikk }}$ & $-0.416^{6 * 4}$ & $-0.074^{*+*}$ \\
\hline o bservations & 544 & 1429 & 1427 & 1442 & 1441 \\
\hline \multicolumn{6}{|l|}{ Earnings growth ${ }^{(4)}$} \\
\hline (1) Standard Controls & -0.001 & 0.001 & $0.018 *$ & -0.005 & $0.004^{* *}$ \\
\hline (2) + background controls & -0.001 & $0.001^{*}$ & $0.018^{* *}$ & -0.006 & $0.004^{* *}$ \\
\hline O bservations & 6013 & 20545 & 20550 & 20718 & 20735 \\
\hline \multicolumn{6}{|l|}{ M ean Labour Supply(5) } \\
\hline (1) Standard Controls & 0.061 & $-0.274^{* * *}$ & $-7.041^{* * *}$ & $-6.235^{* * *}$ & $-1.529^{*+*}$ \\
\hline (2) + background controls & 0.196 & $-0.258^{\text {wat }}$ & $-6.499^{\text {tok }}$ & $-5.876^{n+k}$ & $-1.461^{* * *}$ \\
\hline O bservations & 618 & 1981 & 1978 & 1997 & 1930 \\
\hline \multicolumn{6}{|l|}{ Poverty Rate } \\
\hline (1) Standard Controls & $-0.186^{*}$ & -0.039 & 0.192 & 0.098 & $0.181^{* *}$ \\
\hline (2) + background controls & -0.164 & -0.023 & 0.271 & 0.169 & $0.206 *$ \\
\hline O bservations & 430 & 1663 & 1663 & 1678 & 1678 \\
\hline \multicolumn{6}{|l|}{ Time to first marriage } \\
\hline Marriage Controls(6) & 0.036 & $0.024^{*}$ & -0.186 & 0.168 & 0.037 \\
\hline O bservations & 2848 & 7898 & 7919 & 7981 & 7974 \\
\hline
\end{tabular}

N otes: See below 
Table 3b: Regression Results: Black Men

\begin{tabular}{|c|c|c|c|c|c|}
\hline Dependent Variable: & $\begin{array}{c}\text { Under } 18 \\
\text { alcohol use }\end{array}$ & $\begin{array}{c}\begin{array}{c}\text { Marijuana } \\
\text { Use }\end{array} \\
\end{array}$ & $\begin{array}{c}\text { Heavy D rugs } \\
\text { Use }\end{array}$ & Violence & $\begin{array}{l}\text { Extreme } \\
\text { Violence }\end{array}$ \\
\hline \multicolumn{6}{|l|}{ Log earnings at age 28} \\
\hline (1) Standard Controls(1) & 0.043 & 0.024 & $-0.922^{4 * *}$ & 0.153 & $-0.063^{*}$ \\
\hline (2) + background controls ${ }^{(2)}$ & 0.034 & 0.018 & $-0.878^{w * *}$ & 0.070 & $-0.080^{* *}$ \\
\hline o bservations & 213 & 699 & 692 & 701 & 702 \\
\hline \multicolumn{6}{|l|}{ M ean log earnings ${ }^{(3)}$} \\
\hline (1) Standard Controls & 0.028 & 0.003 & $-0.859^{* *}$ & -0.021 & $-0.060^{*}$ \\
\hline (2) + background controls & 0.014 & 0.008 & $-0.814^{* *}$ & 0.026 & $-0.062^{*}$ \\
\hline O bservations & 262 & 707 & 696 & 711 & 712 \\
\hline \multicolumn{6}{|l|}{ Earnings growth ${ }^{(4)}$} \\
\hline (1) Standard Controls & 0.001 & 0.000 & 0.024 & 0.014 & $-0.009^{\text {wak }}$ \\
\hline (2) + background controls & 0.002 & -0.001 & 0.028 & 0.011 & $-0.011^{* * *}$ \\
\hline O bservations & 2632 & 8636 & 8572 & 8672 & 8694 \\
\hline \multicolumn{6}{|l|}{ M ean Labour Supply(5) } \\
\hline (1) Standard Controls & -0.533 & $-0.473^{* *}$ & -7.231 & $-6.199^{*}$ & $-1.513^{\text {tok }}$ \\
\hline (2) + background controls & -0.560 & -0.332 & -6.421 & -5.224 & $-1.329^{\text {wat }}$ \\
\hline O bservations & 296 & 885 & 875 & 889 & 891 \\
\hline \multicolumn{6}{|l|}{ Poverty Rate } \\
\hline (1) Standard Controls & -0.051 & -0.044 & 0.676 & -0.390 & 0.133 \\
\hline (2) + background controls & -0.029 & -0.048 & 0.468 & -0.617 & 0.143 \\
\hline o bservations & 208 & 661 & 655 & 663 & 663 \\
\hline \multicolumn{6}{|l|}{ Time to first marriage } \\
\hline Marriage Controls(6) & 0.066 & 0.017 & -0.300 & -0.501 & -0.015 \\
\hline O bservations & 1441 & 4265 & 4224 & 4285 & 4303 \\
\hline
\end{tabular}

N otes: See below 


\section{N otes to Table 3}

Each cell in table 3 reports the result of a separate regression of the row variable as the dep variable as the main variable of interest, with additional controls as specified in the row; the $n$ the variable of interest. Thus the top-left number of table 3a shows that regressing log earnin and standard earnings function controls produces a coefficient of 0.023 for white men.

Significance is indicated by: ${ }^{*}$ significant at $10 \%,{ }^{* *}$ significant at $5 \%,{ }^{* * *}$ significant at $1 \%$

The variables under 18 alcohol use, marijuana use, extreme violence and runaway were treated a health shock is naturally dichotomous; heavy drugs use and violence are created dichotomous v respondent answered "More than 50 times" and therefore indicate high levels of the activity.

(1) These are years of education, local unemployment rate, marital status, number of depender

(2) These are whether mother completed high school, whether mother worked when re completed high school, whether father worked when respondent aged 14, whether respor 14, whether respondent had a religious up-bringing, whether respondent lived in the sout whether respondent lived in an urban area in 1980 (when the behavioural questions were a

(3) This is the mean of log earnings over the period 1981 to 1992.

(4) Pooling the panel dataset into an N*T dataset, log earnings are regressed on the standard 1 squared, the variable of interest and the variable of interest interacted with age. It is this I and captures any change in the age-earnings profile induced by the behaviour under consic

(5) This is mean weeks worked per year between 1981 to 1992.

(6) These are education, age and age squared, a measure of belief in traditional gender ro income, a measure of the wage of potential partners, whether mother completed high scr respondent aged 14, whether father completed high school, whether respondent lived whether respondent had a religious up-bringing. 
Table 4a: Regression Results: White M en

\begin{tabular}{lcccc}
\hline Dependent Variable: & M arijuana Use & $\begin{array}{c}\text { Heavy D rugs } \\
\text { Use }\end{array}$ & Violence & E) \\
Vi
\end{tabular}

Log earnings at age 28

(1) Standard Controls(1)

0.009

$-0.203^{*}$

$-0.673^{\text {tw* }}$

(2) + background controls $s^{(2)}$

0.005

$-0.185^{*}$

$-0.673^{\text {tw* }}$

O bservations

1547

M ean log earnings(3)

(1) Standard Controls

$0.017^{* *}$

$-0.361^{\text {*** }}$

$-0.283^{*}$

$-0.014^{*}$

$-0.325^{\text {*a* }}$

$-0.261^{*}$

(2) + background controls

O bservations

1417

Earnings growth ${ }^{(4)}$

(1) Standard Controls

(2) + background controls

0.000

0.011

$-0.013$

O bservations

0.000

0.01

$-0.013$

20383

M ean Labour Supply(5)

(1) Standard Controls

(2) + background controls

$-0.090$

$-5.337^{\text {k*t }}$

$-2.807$

$-0.079$

$-4.932^{\text {tw+ }}$

$-2.664$

1964

Poverty Rate

(1) Standard Controls

(2) + background controls

$-0.067$

0.228

$-0.585$

$-0.052$

0.221

$-0.620$

O bservations

1653

Time to first marriage

Marriage Controls(6)

$0.029^{* *}$

$-0.337$

0.112

7823

N otes: See the notes to Table 3; the difference here is that each row reports the results of a singlı variables of interest jointly. 
Table 4b: Regression Results: Black Men

\begin{tabular}{|c|c|c|c|c|}
\hline Dependent V ariable: & $\begin{array}{l}\text { Marijuana } \\
\text { Use }\end{array}$ & $\begin{array}{c}\text { Heavy } \\
\text { Drugs Use }\end{array}$ & Violence & $\begin{array}{l}\text { Ext } \\
\text { Vio }\end{array}$ \\
\hline \multicolumn{5}{|l|}{ Log earnings at age 28} \\
\hline $\begin{array}{l}\text { (2) + background controls(2) } \\
\text { O bservations }\end{array}$ & $0.030^{*}$ & $-0.840^{\text {*k }}$ & $\begin{array}{r}0.219 \\
681\end{array}$ & -0 . \\
\hline \multicolumn{5}{|l|}{ M ean log earnings(3) } \\
\hline (1) Standard Controls & 0.014 & $-0.795^{* *}$ & 0.073 & -0 . \\
\hline $\begin{array}{l}\text { (2) + background controls } \\
\text { O bservations }\end{array}$ & 0.019 & $-0.775^{* *}$ & $\begin{array}{r}0.149 \\
684\end{array}$ & -0 . \\
\hline \multicolumn{5}{|l|}{ Earnings growth ${ }^{(4)}$} \\
\hline $\begin{array}{l}\text { (1) Standard Controls } \\
\text { (2) + background controls }\end{array}$ & $\begin{array}{l}0.000 \\
0.000\end{array}$ & $\begin{array}{l}0.042 \\
0.051\end{array}$ & $\begin{array}{l}0.012 \\
0.007\end{array}$ & $\begin{array}{l}-0.1 \\
-0.1\end{array}$ \\
\hline \multicolumn{4}{|l|}{ M ean Labour Supply(5) } & \\
\hline (1) Standard Controls & -0.333 & -3.704 & -3.670 & $-1 .:$ \\
\hline $\begin{array}{l}\text { (2) + background controls } \\
\text { O bservations }\end{array}$ & -0.215 & -3.798 & $\begin{array}{c}-2.566 \\
859\end{array}$ & -1 . \\
\hline \multicolumn{5}{|l|}{ Poverty Rate } \\
\hline (1) Standard Controls & -0.053 & 0.629 & -0.536 & 0. \\
\hline $\begin{array}{l}\text { (2) + background controls } \\
\text { O bservations }\end{array}$ & -0.060 & 0.450 & $\begin{array}{c}-0.750 \\
645\end{array}$ & 0. \\
\hline \multicolumn{5}{|l|}{ Time to first marriage } \\
\hline $\begin{array}{l}\text { Marriage Controls(6) } \\
\text { O bservations }\end{array}$ & 0.017 & -0.284 & $\begin{array}{r}-0.661 \\
4154\end{array}$ & -0 \\
\hline
\end{tabular}

N otes: See the notes to Table 3; the difference here is that each row reports the results of a singl variables of interest jointly. 


\section{Figure 1: M ean Log Earnings, M ales, High School G raduates}

Note: 'Sometimes' means the activity took place between once and five times in a year; 'Frequently' means 6 or more times in a year. The questions on alcohol consumption and running away from home were only asked of respondents under the age of 18 in 1980. Precise wording of the questions is given in the text of the paper.

\section{(1) Extreme Violence}

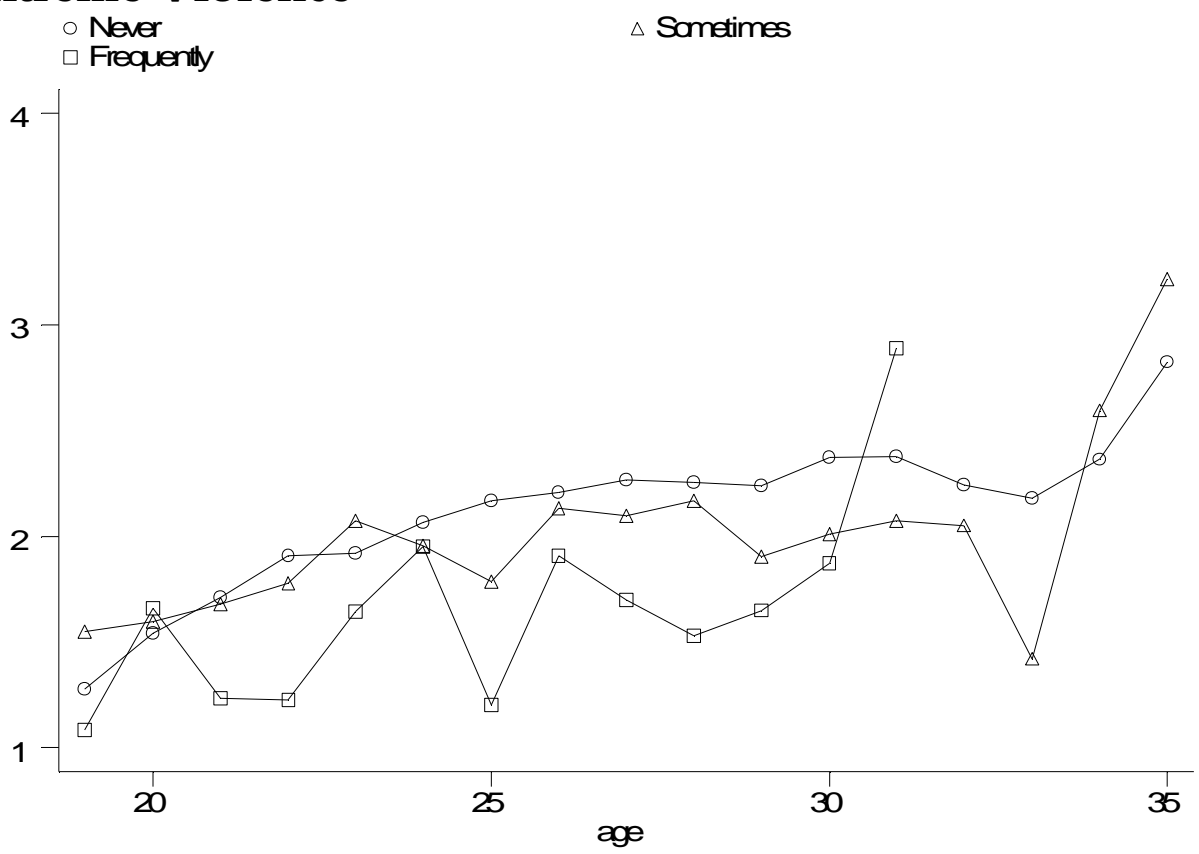

Black

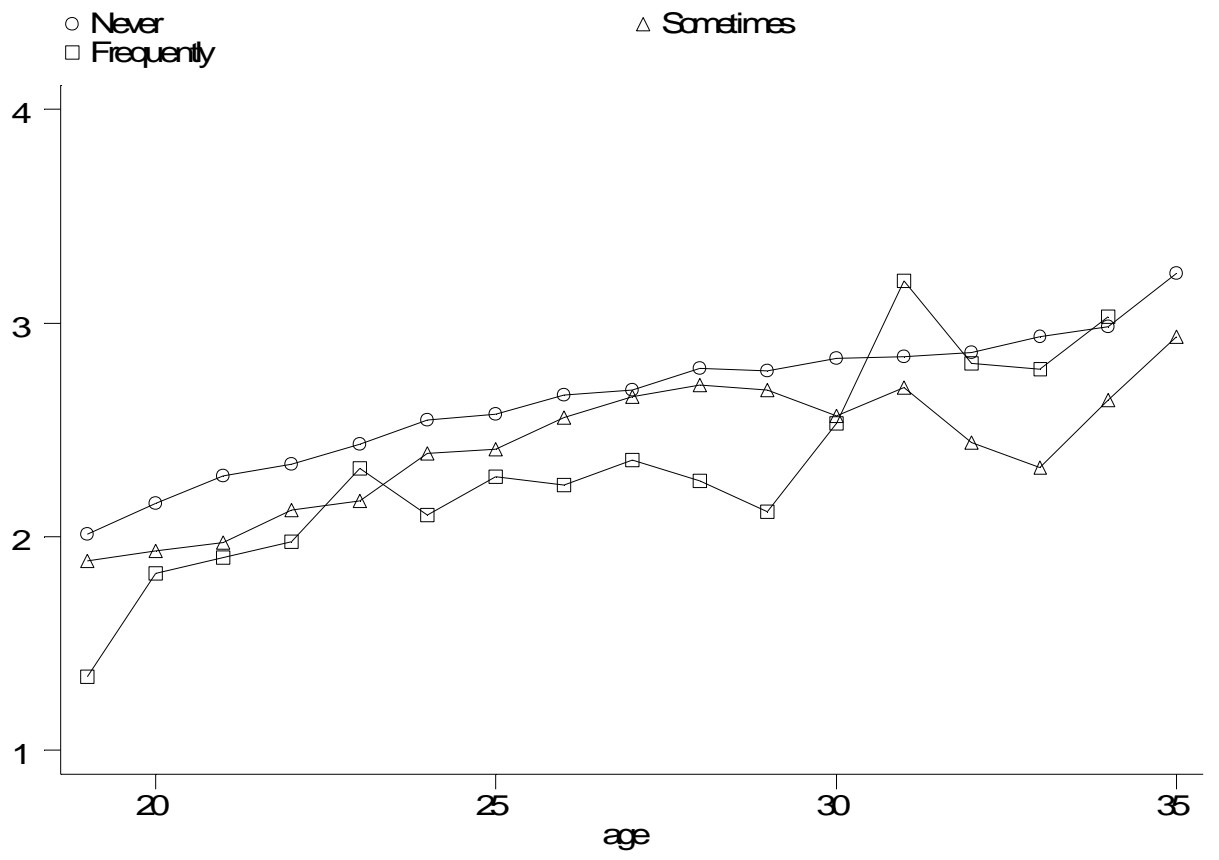

White 
(2) D rug Use

- Never

$\square$ Frequently

$\triangle$ Sometimes

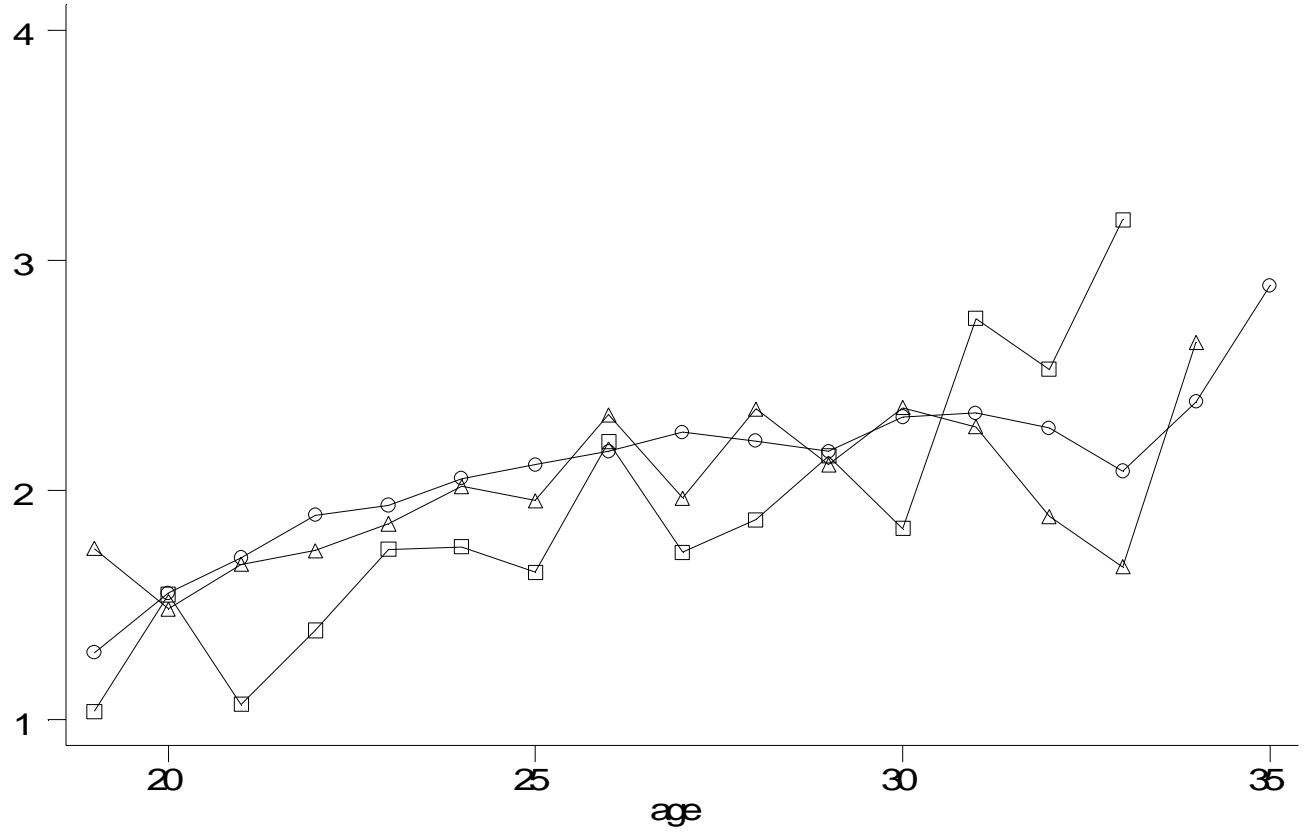

Black

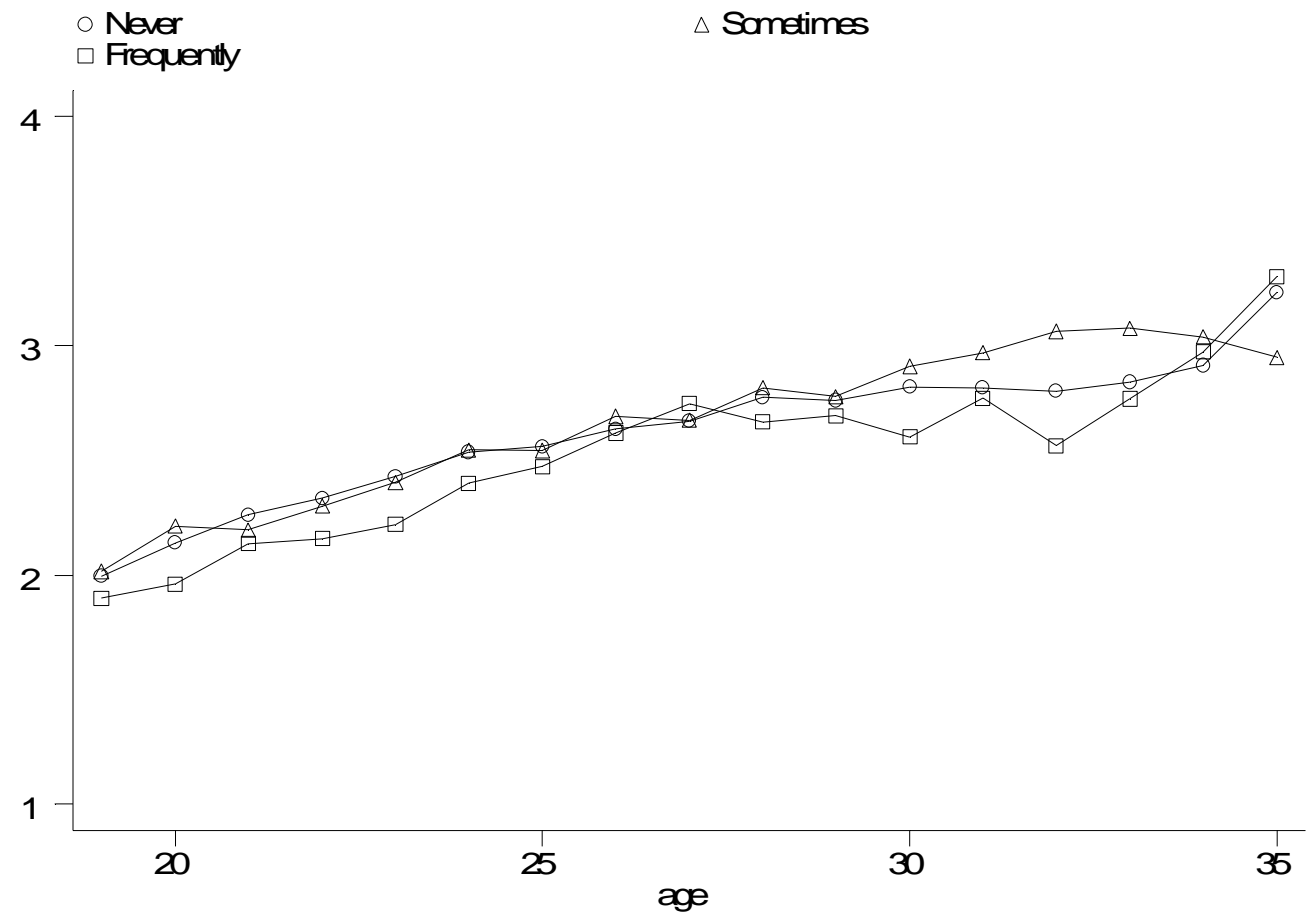

White 


\section{(3) Hash}

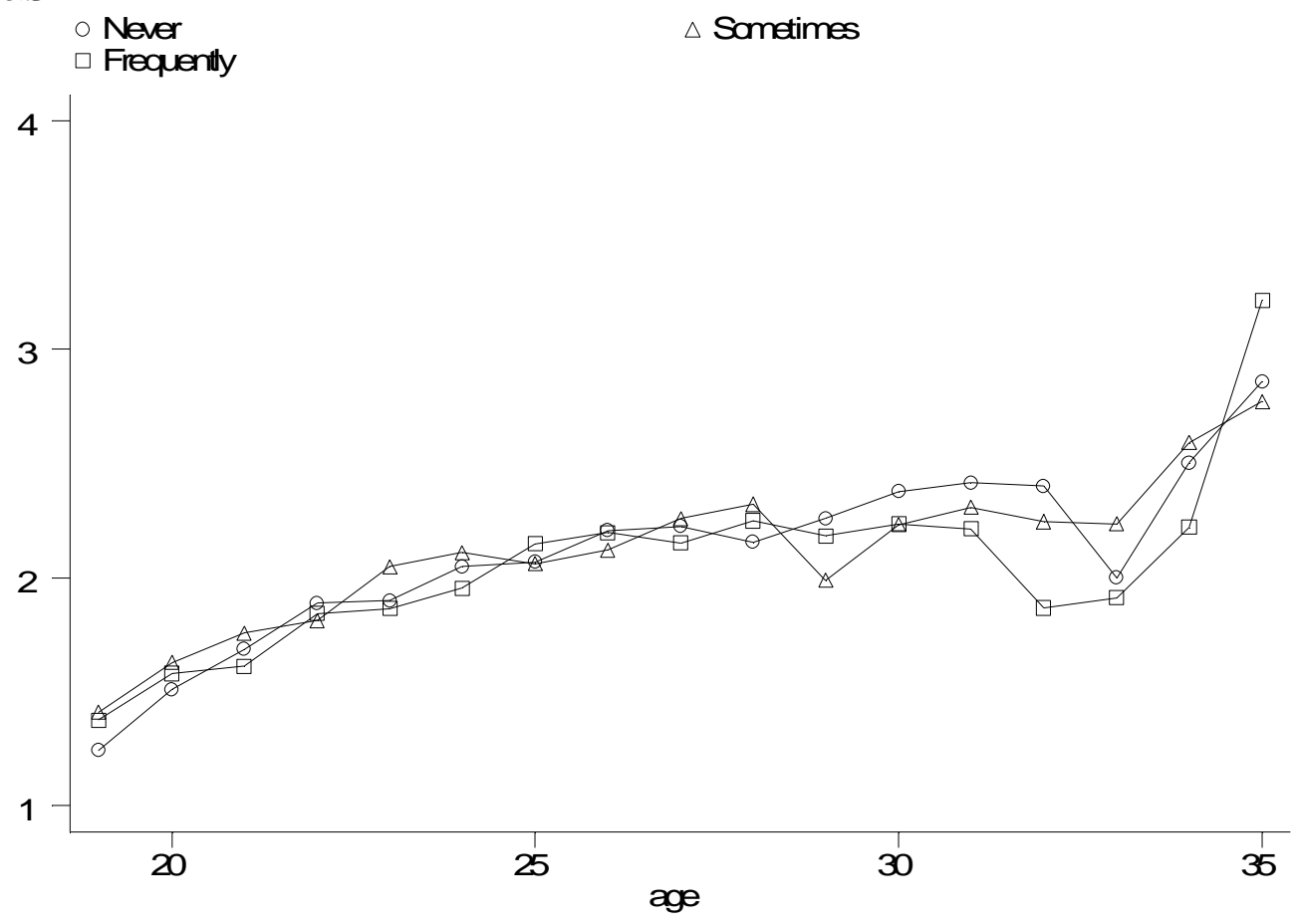

Black

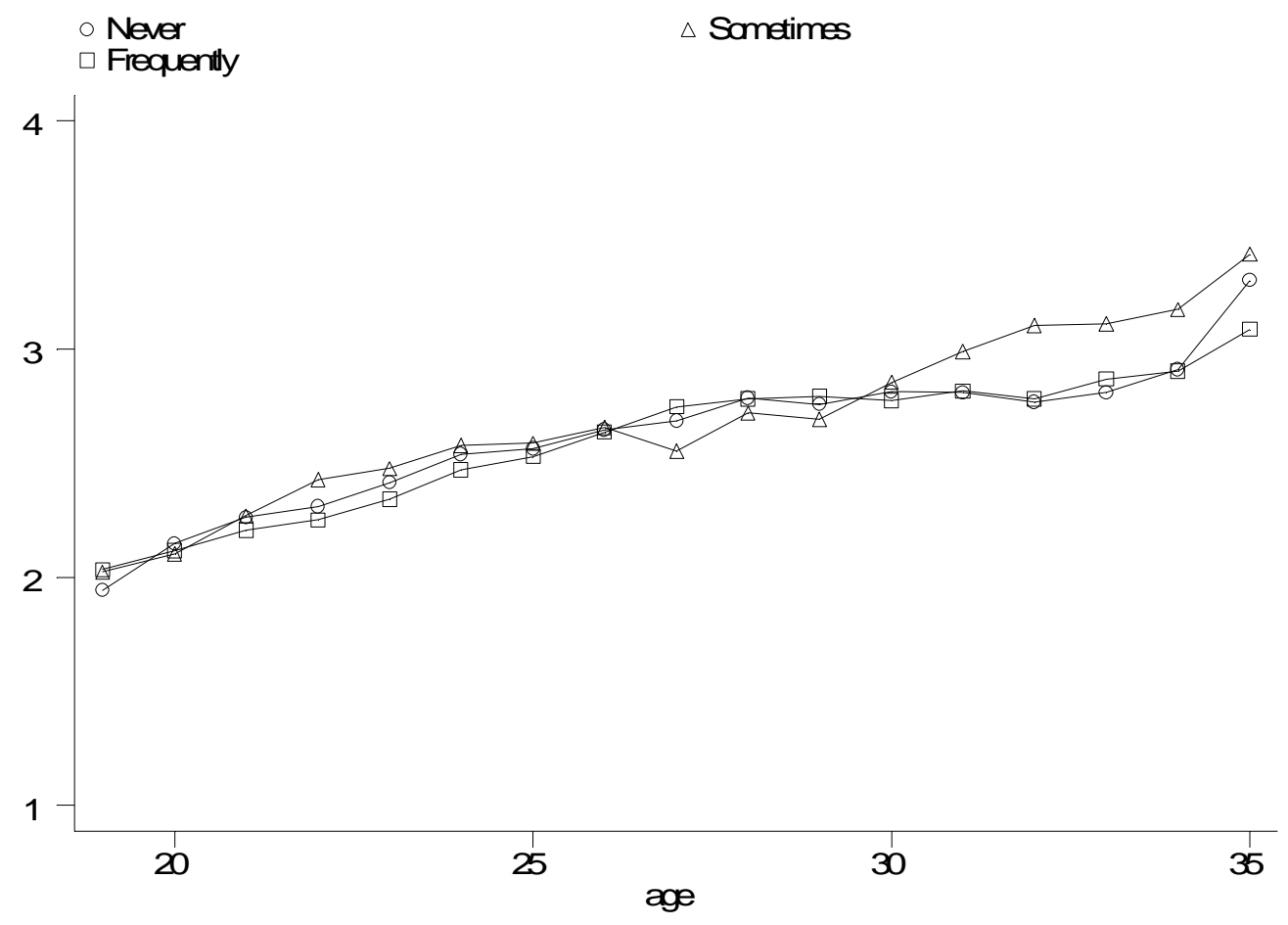




\section{(4) Alcohol}

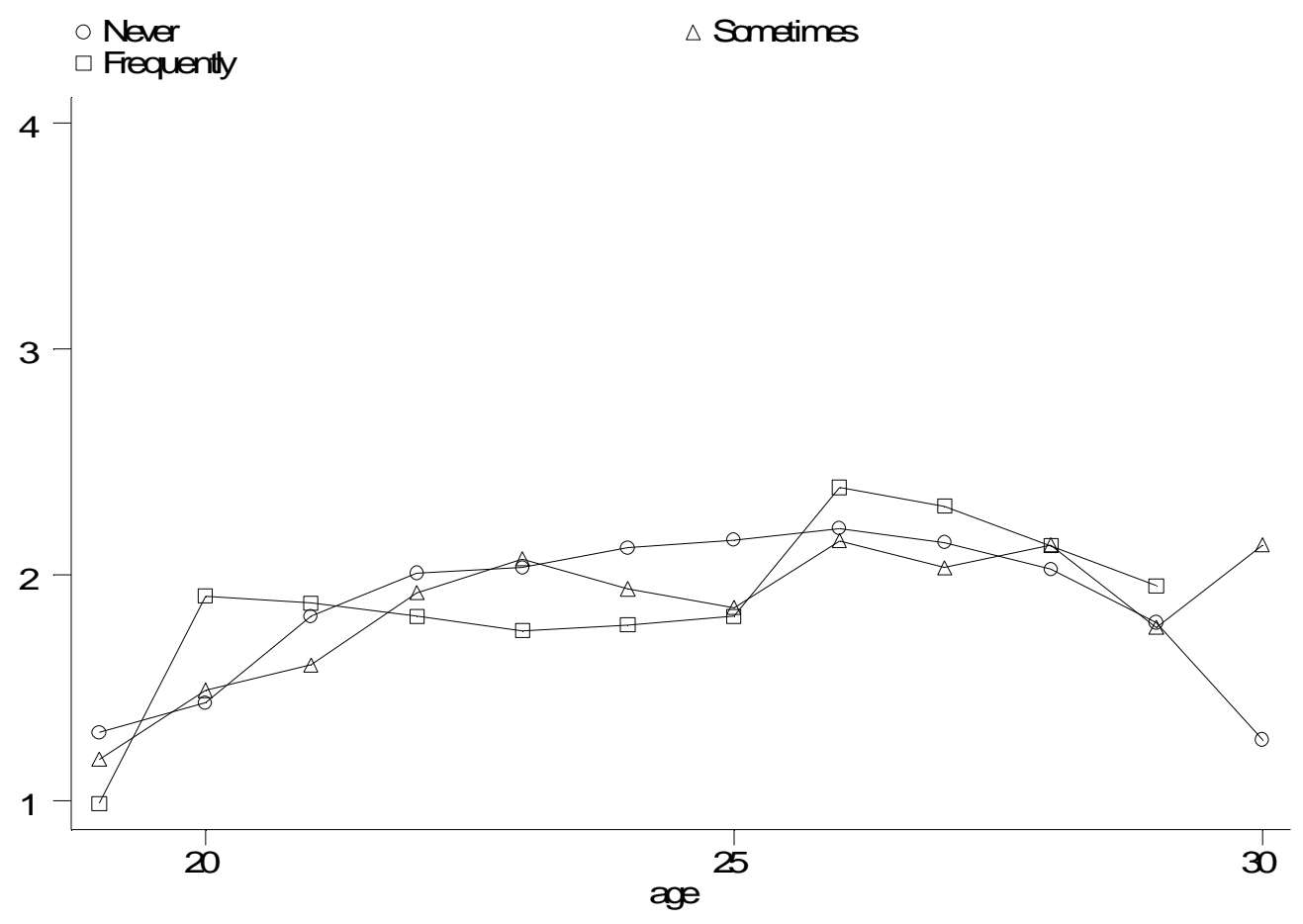

Black

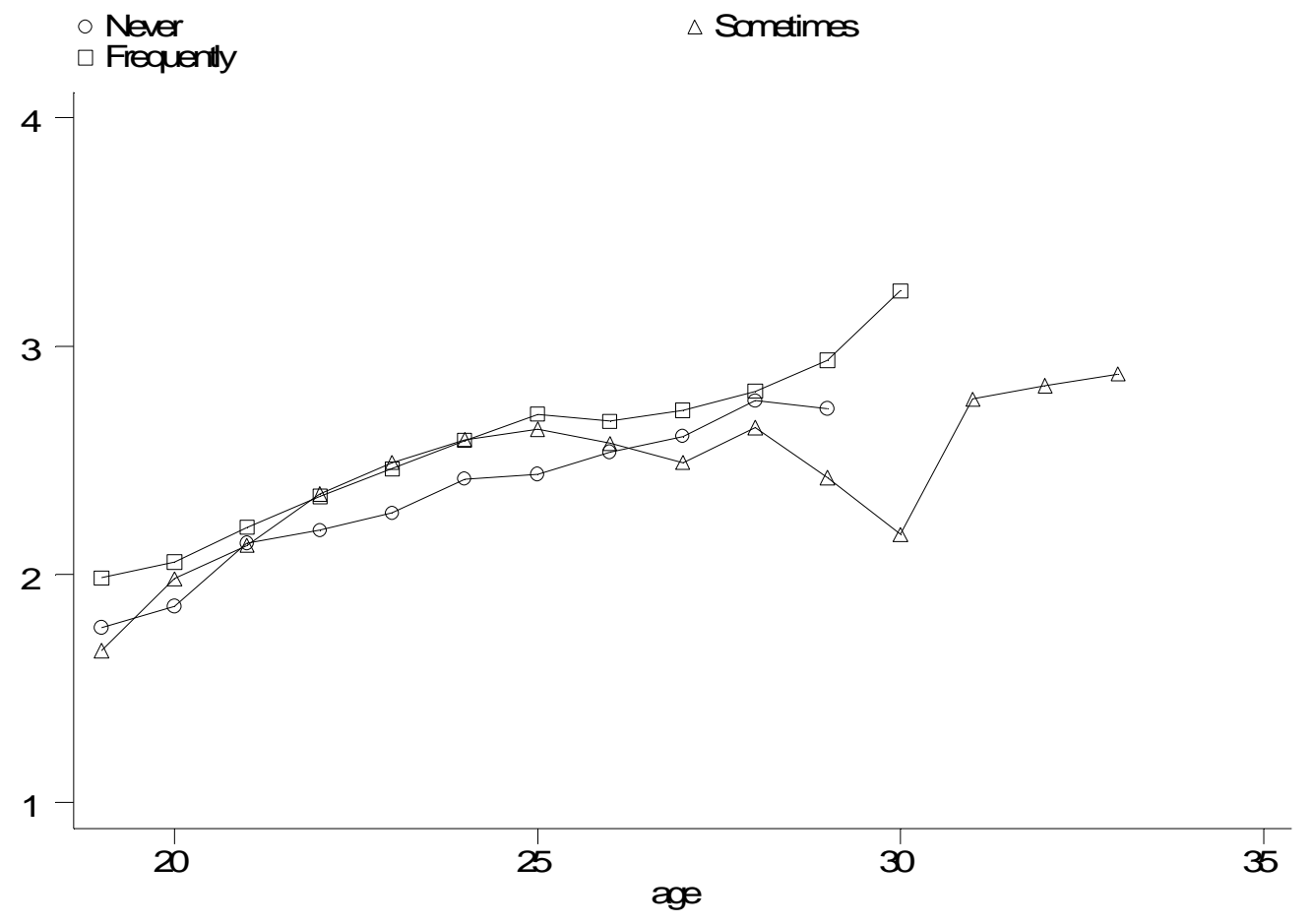

White 
(5) Violence

$\circ$ Never
$\square$ Frequently

$\triangle$ Sometimes

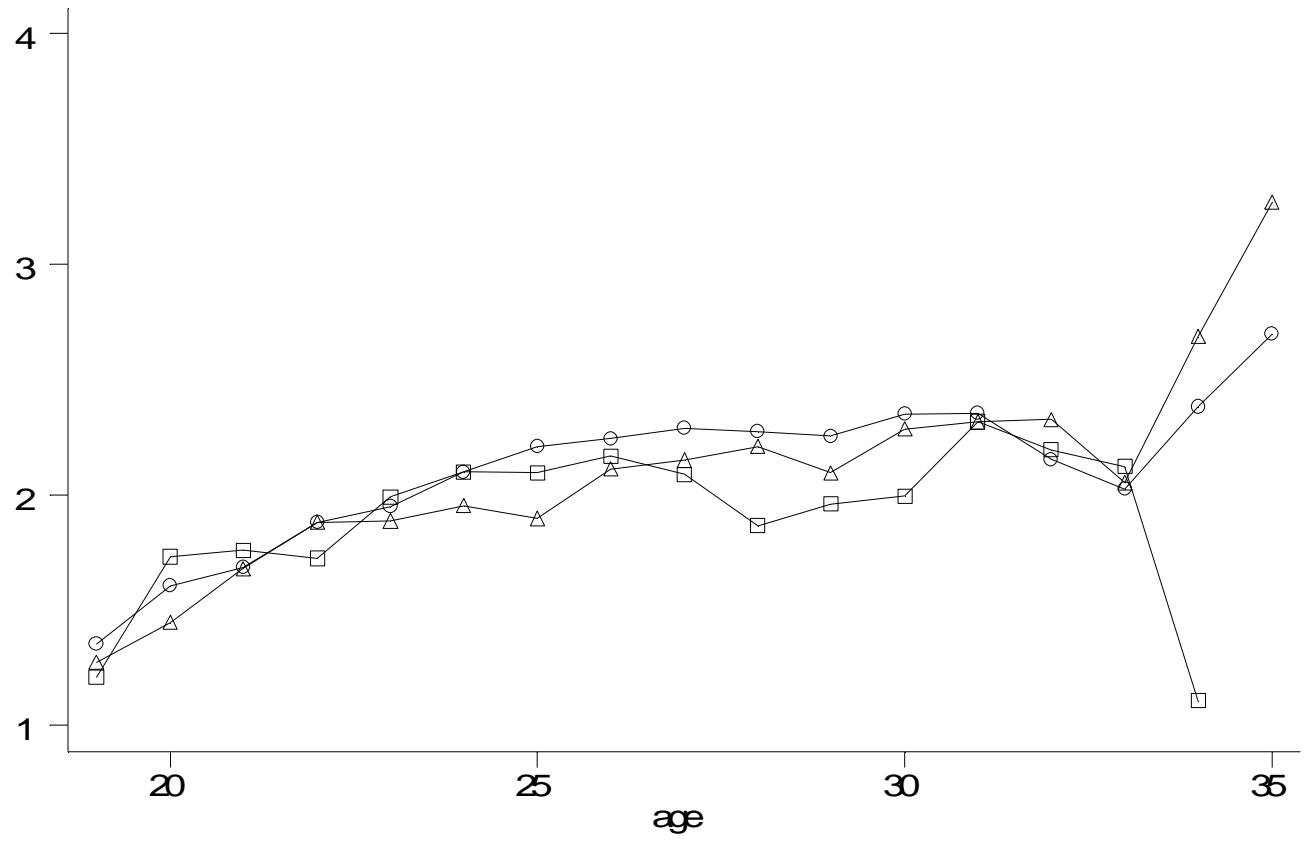

Black

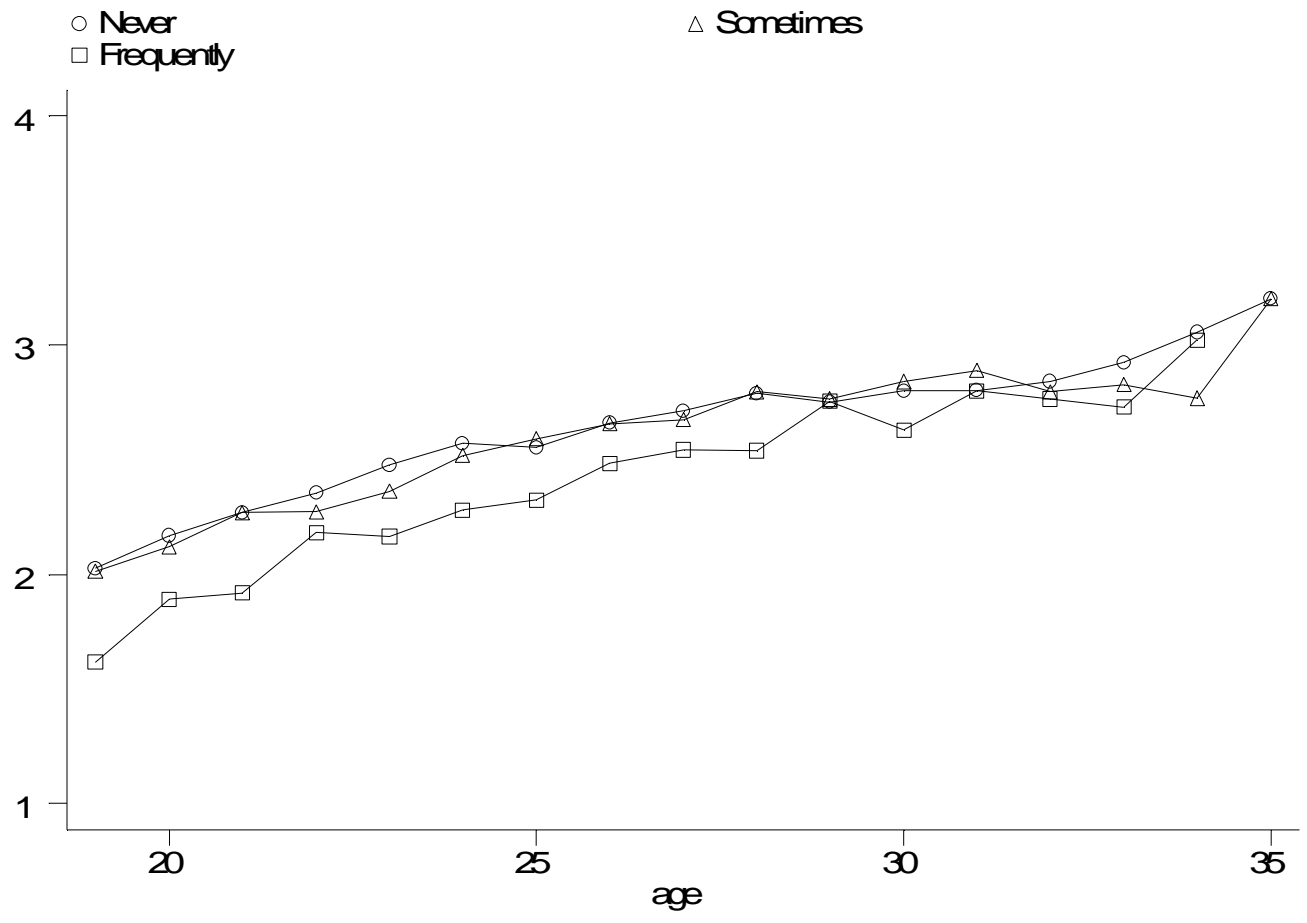

White 
(6) Runaway from home

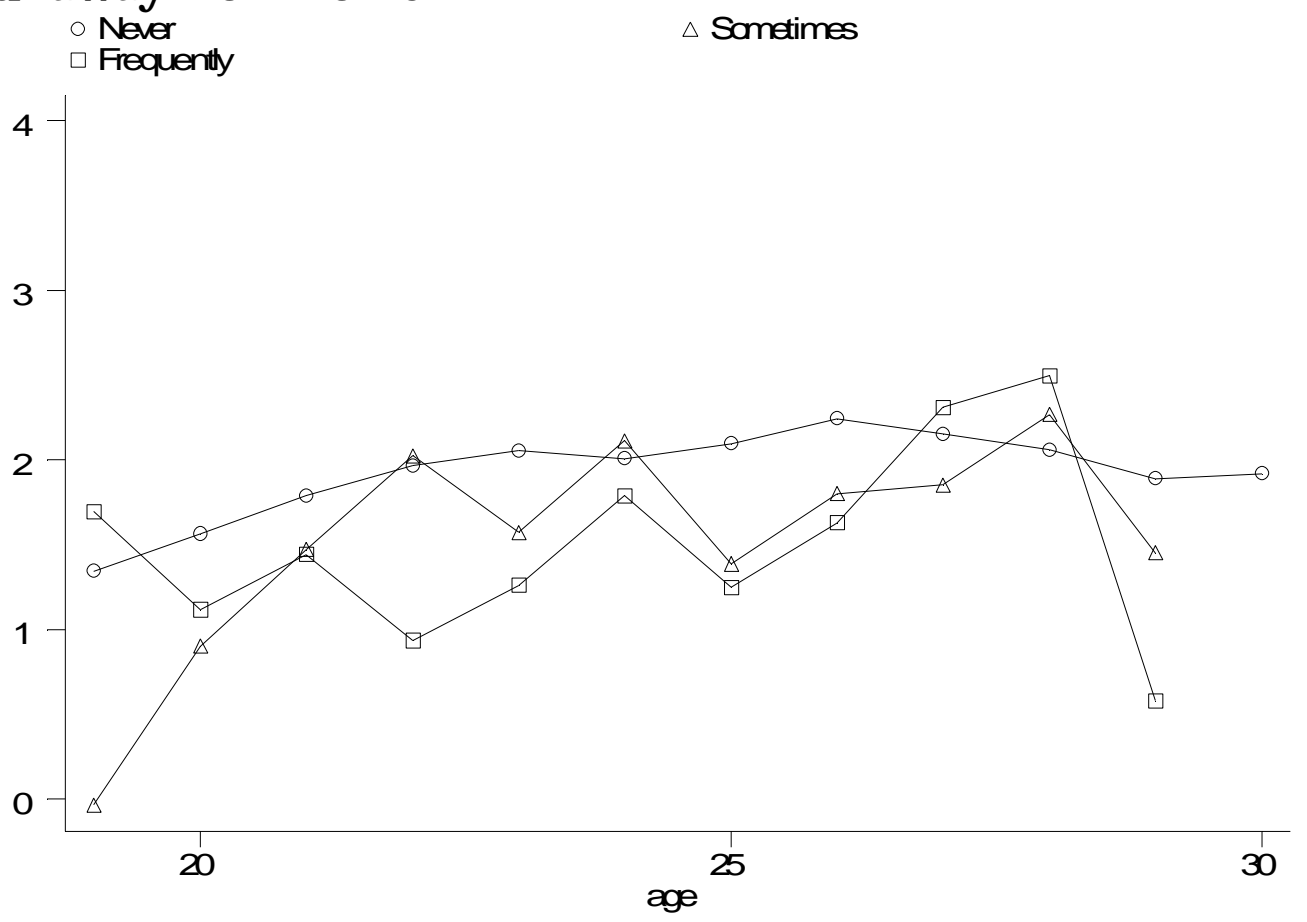

Black

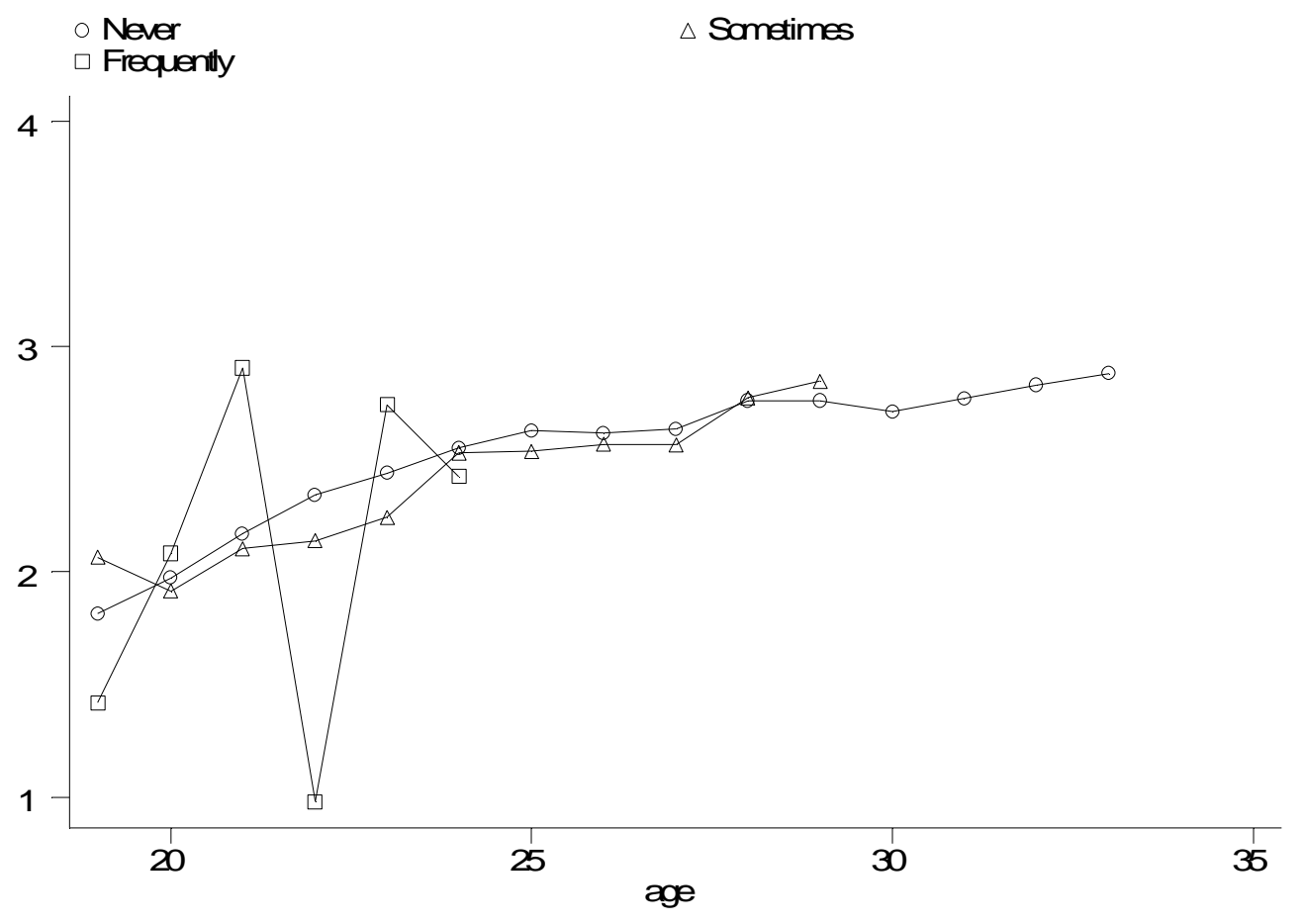

White 
(7) Early work-related health shocks

$\circ \mathrm{Nb}$

$\triangle \mathrm{Yes}$

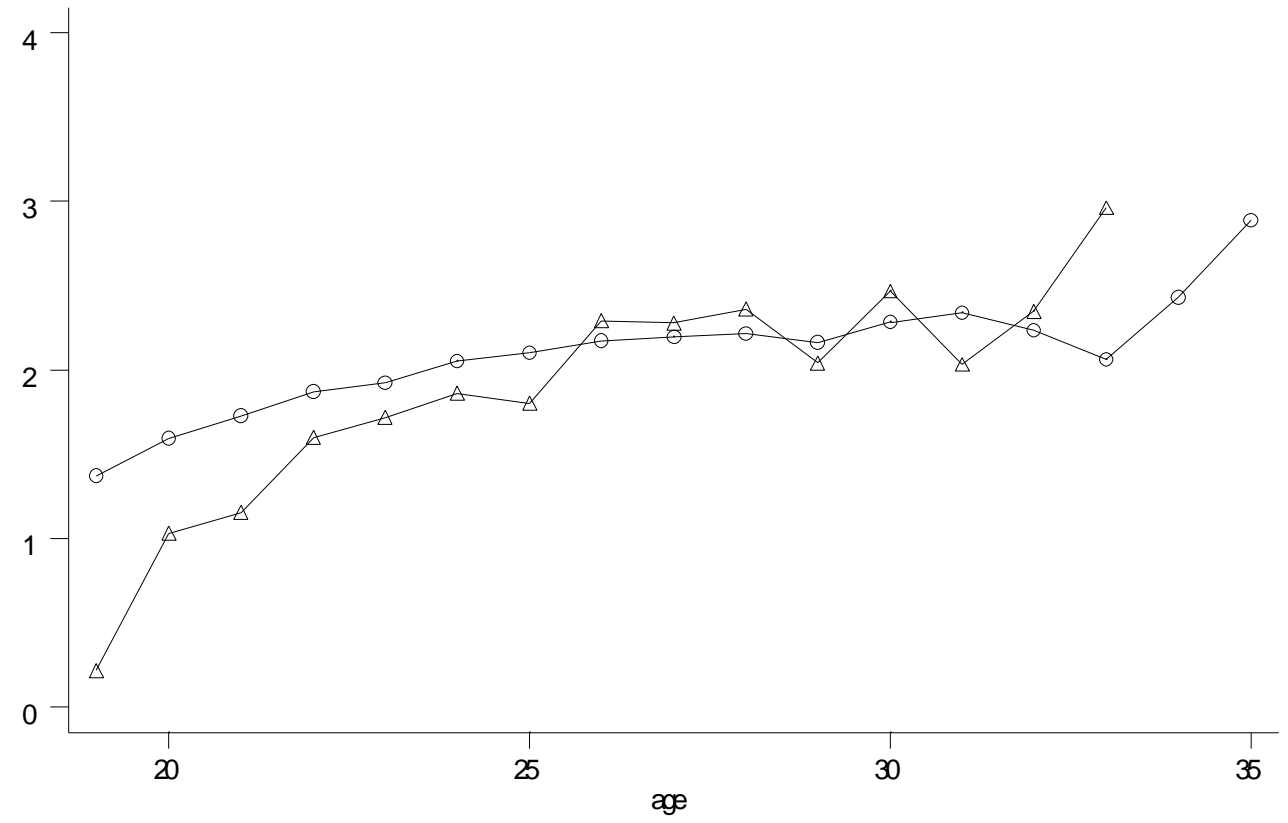

Black

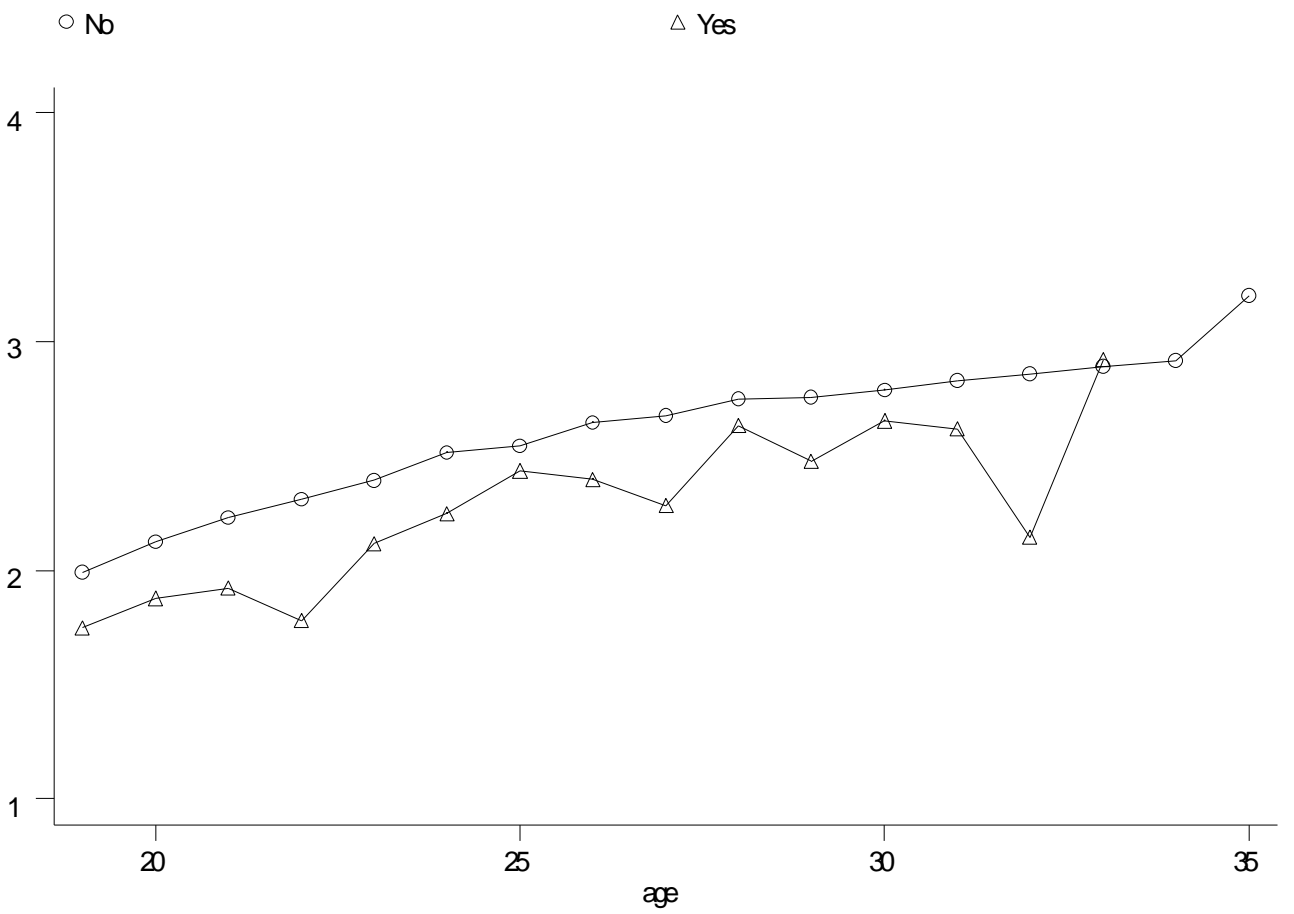

White 


\section{A ppendix Table}

Statistics for the background variables.

\begin{tabular}{lccc}
\hline Variable & No. of O bs & M ean & Std. D ev. \\
\hline Mother is high school drop-out & 2969 & .2764464 & .4473155 \\
Father is high school drop-out & 2969 & .3074783 & .461527 \\
Lived with both parents at 14 & 2969 & .7601342 & .4270734 \\
Had religious upbringing & 2969 & .5412635 & .4983784 \\
Lived in urban area in 1980 & 2965 & .7547758 & .4302926 \\
Lived in the South at 14 & 2880 & .3070597 & .4613545 \\
Mother worked full-time at 14 & 2969 & .6032532 & .489305 \\
Father worked full-time at 14 & 2969 & .8102761 & .3921486 \\
Number of siblings & 2966 & 3.063149 & 1.708767 \\
\hline \hline
\end{tabular}

Weighted using sample weights 